\title{
Do grammars change when they leak?
}

Link to publication record in Manchester Research Explorer

\section{Citation for published version (APA):}

Denison, D. (2004). Do grammars change when they leak? In C. Kay, S. Horobin, \& J. Smith (Eds.), New perspectives on English historical linguistics: Selected papers from 12 ICEHL, Glasgow, 21-26 August 2002, vol. 1, Syntax and morphology (Vol. 1, pp. 15-29). (Current Issues in Linguistic Theory; Vol. 251). John Benjamins Publishing Company.

\section{Published in:}

New perspectives on English historical linguistics

\section{Citing this paper}

Please note that where the full-text provided on Manchester Research Explorer is the Author Accepted Manuscript or Proof version this may differ from the final Published version. If citing, it is advised that you check and use the publisher's definitive version.

\section{General rights}

Copyright and moral rights for the publications made accessible in the Research Explorer are retained by the authors and/or other copyright owners and it is a condition of accessing publications that users recognise and abide by the legal requirements associated with these rights.

\section{Takedown policy}

If you believe that this document breaches copyright please refer to the University of Manchester's Takedown Procedures [http://man.ac.uk/04Y6Bo] or contact uml.scholarlycommunications@manchester.ac.uk providing relevant details, so we can investigate your claim.

\section{OPEN ACCESS}


Denison, David. 2004. Do grammars change when they leak? In Christian J. Kay, Simon Horobin \& Jeremy Smith (eds.), New perspectives on English historical linguistics: Selected papers from 12 ICEHL, Glasgow, 21-26 August 2002, vol. 1, Syntax and morphology (Current Issues in Linguistic Theory 251), 15-29. Amsterdam: John Benjamins. http://benjamins.com/\#catalog/books/cilt.251

\section{Do grammars change when they leak ${ }^{1}$}

\section{Introduction}

The organisation of this programmatic paper is as follows. Limitations of space mean that the treatment is necessarily both selective and allusive. Some general remarks about language change $(\S 1)$ are followed by criticism of the conventional view of synchronic grammar (§2) and a consideration of reanalysis in diachrony (§3). I then discuss 'leakiness' of the grammar of the English NP in synchronic terms (§4) and suggest graduated change as a plausible alternative to reanalysis for some kinds of diachronic change ( $\$ 5)$. The appearance and loss of intermediate forms are considered in $\S \S 6-7$, and my example of reanalysis reappears in the conclusion $(\S 8)$.

\section{A typology of language change ${ }^{2}$}

All living languages are subject to change. How do they change? Most linguists now distinguish between actuation or innovation on the one hand and propagation or diffusion on the other. Diffusion is the spread of a variant from the point where it has become an option for a number of speakers. Diffusion of change requires the prior existence of variants - alternative ways of saying the same thing. Some variation appears to be stable 
over long periods (Raumolin-Brunberg 2002): variation is a necessary but not a sufficient condition for change to occur.

And why does language change? The answer to this question is, of course, dependent on the theoretical position of the analyst. If the most salient property of language is its grammar, an internalised set of rules unconsciously built up and used by an individual speaker-hearer, then language change may be seen as a consequence of new generations inducing a slightly different grammar from that internalised by their parents' generation, perhaps because of a slightly changed preponderance of some usage, the cause of which is not really grammatical in origin but some contingent 'performance' factor. The new grammar in turn leads to a further change in the output of its speakers, and so things move on. The process of language acquisition in childhood will be critical, and the favoured form of analysis will (usually) be formal and structural. Alternatively, if language is something which crucially belongs to and exists in a speech community, then speaker interaction and relative social status may be the fundamental engines of language change. Speakers may adjust their usage to (or against) community norms throughout adolescence and perhaps beyond, and change is not confined to the acquisition process. The requisite analysis will be sociolinguistic and statistical. Then again, if speakers and hearers are regarded as autonomous individuals, anxious above all to maximise their communicative efficiency, yet other considerations may be identified, typically involving speaker intentions.

We can group three main types of force for change under the headings structural, social and functional. Each has its own champions in the literature, though the dividing lines are not always clear-cut. Beyond these three broad categories there are 
Denison, 'Grammars ... leak', p.3 of 22

extralinguistic factors to consider too. Here I will mainly be looking at change from the structural and functional points of view. For a fuller discussion see Croft (2000).

\section{Synchrony without leakage}

Many approaches to synchronic language description start from the working hypothesis that grammars don't leak. That is, there are a certain number of parts of speech or word classes (the number may depend on the theory or the analyst), and every word in a particular utterance of a sentence belongs to just one of them. Constituent structure analysis gives a unique bracketing of these words. (In a theory with movement there may be a series of structures in the derivational history.) Utterances which appear not to fit are either

- ignored,

- or arbitrarily made to fit,

- or assumed to be in need of a better analysis which remains to be discovered,

- or relegated to 'mere' performance (or E-language),

- or - in extremis - accepted as anomalous but regarded as minor and peripheral parts of the language system.

This is unfair to many linguists, but as far as mainstream formal syntax is concerned, not entirely unjustified.

What utterances don't fit? Here is a simple example. If we consider the sentences

(1) Jim bought a watch in the market.

(2) Jim put his bicycle in the shed. 
(3) Jim gave money to charity.

(4) Jim took pleasure in mathematics.

(5) Jim paid attention to his teacher.

(6) Jim set fire to the car.

we find that each has different properties despite its superficially similar $\mathrm{NP}_{1} \mathrm{~V} \mathrm{NP}_{2} \mathrm{PP}$ structure. For example, the PP in (1) is an adjunct, whereas the PPs in (2) and (3) are generally regarded as complements; in (3), though, but not (2), the PP commutes with an indirect object. The PP of (4) is syntactically somewhat equivocal — adjunct or complement? - while at the lexical level one might recognise take pleasure in as a transitive group-verb equivalent to enjoy. Similar remarks could be made about (5), though the syntax is not identical: (5) passivises much more readily. So does (6), but now the verbal idiom is closer to being frozen and $\mathrm{NP}_{2}$ is not open to modification; indeed we could ask whether it makes sense to assign fire to the word class Noun at all. We could go on adding sentences with shades of variation and subtly different behaviour until a structuralist model ran out of ways of distinguishing items. The working hypothesis cannot be upheld.

\section{Reanalysis}

Even a watertight system of synchronic analysis still gives many possibilities of change by creation of variants and selective preference among them. One such route is by reanalysis. We need an example. There was (and still is) a prepositional verb run over:

(7) The rabbit ran over the meadow. 
(8) My car ran over a bottle (lying in the road).

(9) $\left[\mathrm{VP} \operatorname{ran}_{\mathrm{intr}}[\mathrm{PP}\right.$ over $[\mathrm{NP}$ a bottle $]]$

Over is a preposition. However, the same linear string, ran over a bottle, is in principle open to reanalysis in English so that over becomes an adverbial particle in a transitive phrasal verb:

(10) [VP $\operatorname{ran}_{\text {trans }}[$ part over] [NP a bottle] ]

(As it happens, no one has come up with a wholly satisfactory formal analysis of either prepositional or phrasal verbs, so the reader's pet analyses won't necessarily be the same as mine in (9) and/or (10). All that is needed is agreement that analyses of the two should be different from each other.)

Why should this reanalysis take place? It is actually unlikely in the context of (8) but far more likely if the pragmatic situation is:

(11) My car ran over a bottle (standing in the road). This time the bottle is definitely affected by the action: it will be knocked over and in all probability broken. Hence the re-interpretation of over: it need no longer refer to the trajectory of the car across and above the obstacle; now it can refer to the trajectory of the bottle away from the upright position and is resultative. Thus run over is no longer a prepositional verb like run into, but a phrasal verb like knock over. It has been reanalysed, in this instance both semantically and syntactically. Of course, sadly, we take more interest in such things when the victim is human:

(12) A drunk driver ran over two pedestrians.

We see the change semantically in that the car need not literally pass on top of its victims. And we see it syntactically in that we will now also begin to attest sentences like 
(13) A drunk driver ran two pedestrians over. not previously possible.

I chose this rather grisly example because the reanalysis is so intuitively clear. Nevertheless it would be unfair to let this example represent all syntactic reanalyses, (a) because this reanalysis is clearly not purely a matter of syntax, and (b) because even without the change in run over (which is historically attested, incidentally), such everyday patterns as go for and work out are rather embarrassing for a syntax without constructions. On the other hand, whether reanalysis ever is purely syntactic is questionable (Bill Croft, personal communication, 2 Dec. 2002). I cannot enter into this question here.

What is the mechanism of reanalysis? I don't mean the technical mechanism, which will depend on the particular syntactic model in use; I mean the social mechanism. In diachrony I take it to be the attribution by a younger generation of choices from the watertight grammar for the analysis of some pattern which differ from the analysis of the older generation, whether different word class assignment or different structure or both. Remember: change implies variation. The variants in this case are implicit ones, alternative structures for the same explicit form, and on the individual level the change occurs during acquisition. Statistically the change will enter the language as the new analysis gradually prevails over time. This is essentially the mechanism of Lightfoot (1979) and many succeeding works.

Another mechanism allows for more than one grammar in a population at the same time. The idea of competing grammars is found in Pintzuk (1991) and other works. It was devised in order to account for explicit variation in synchronic grammar, but I 
guess it could be used for the kind of implicit, underlying variation in the string analysed above. One of my problems with that approach is the prospect of a snowballing multiplicity of grammars to account for all the variation encountered in practice, and allowing it to deal with lexical variation like this would exacerbate that problem enormously.

Yet another approach has been tried for a specific historical problem by Wim van der Wurff (1992), where he imagines a scenario of contact between dialects (or social networks), in which an innovation in one group has to be interpreted in a particular way by speakers of another group with a different grammar who encounter it, leading to reanalysis by them and starting a chain of developments as one group's output is reacted to by another. Something similar was recently suggested by Anthony Warner for the history of $d o$ (2002). Notice here that reanalysis and change is not confined to the acquisition phase. I am very sympathetic in general to accounts which allow for significant changes in an individual's language during adolescence at least and perhaps right through adulthood. But the scenarios demand enormous ingenuity and are necessarily highly speculative.

Although there are difficulties with all these models of reanalysis, I certainly don't wish to reject reanalysis outright. But here I want to follow a different tack. Reanalysis of an individual form moves instantaneously from one watertight analysis to another (even if the consequences take time to play out and/or spread). But synchronic grammar just isn't watertight. The prior assumption is wrong. 


\section{Synchrony leaks}

Edward Sapir's (1921:38) dictum that "All grammars leak" has long been practically a motto of mine, though I (and probably others too) have unintentionally misappropriated it: Sapir was specifically writing about the mapping between form and meaning. It isn't entirely clear that he is endorsing the interpretation which I wish to attribute to the saying, namely that the categories and structures imposed by grammarians on a language are never watertight. ${ }^{3}$ Nevertheless, that is the sense in which I intend my title to be read.

Here I will concentrate on simple NPs. The basic structure used by the Cambridge Grammar (2002:331) is

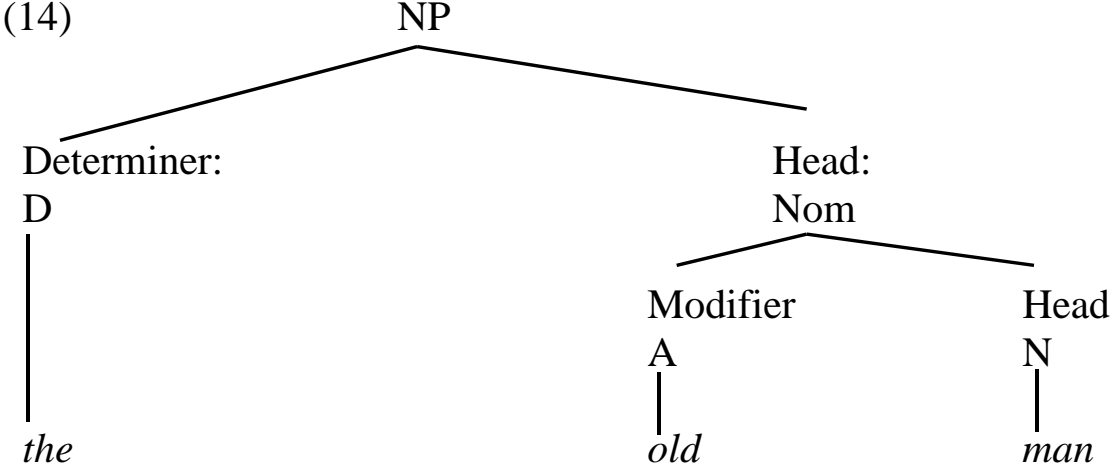

They give reasons for not using the Abney-style DP analysis. And note that they use 'Determiner' for the function, as in (14), whereas I will stick to old habits and use it for the category. Something like the three-way distinction of D, A, N is very widely accepted cross-linguistically and in English grammar, in the majority of frameworks. What does it buy us?

Determiners are function-words, of general semantics (definiteness, quantification, etc.), and mutually exclusive. Adjectives are lexical, content words, and 
can be iterated. 'Lexical' is an imprecise term which tends to involve specificity of meaning and openness of class. A summary of some key properties is given in Table 1. @@insert Table 1 about here

I have added Prn, ${ }^{4}$ since pronouns can act as head of NP, like N, but differ in many other ways, including general incompatibility with D and A. Almost every cell needs a bit of qualification, as we tell our students:

- Prn can co-occur with A in certain circumstances: lucky me, poor you

- $\mathrm{N}$ can iterate, though not as head of NP: pit-head strike ballot

- not all A show comparison: potential, mere

- not all A can occur in predicative position: potential, mere

- $\quad$ some A always occur in predicative position and do not function attributively in NP at all: asleep

So far these subtleties do not vitiate the basic D-A-N analysis of the standard NP. I should emphasise that I think that $\mathrm{D}, \mathrm{A}$ and $\mathrm{N}$ are useful descriptive generalisations, probably with genuine psychological reality. However, in categorial terms it might be interesting to arrange the four categories mentioned so far in the following diagram:

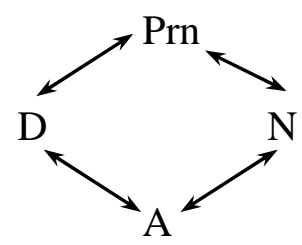

The reason is that every boundary between adjacent categories is leaky in PDE, whereas Prn and A are entirely distinct and so too (I think) D and N. Let me briefly exemplify the shading of one category into another. For the A N boundary I refer to Denison (2001), 
for example the word key, found in PDE at various points along the continuum from clear $\mathrm{N}$ to almost wholly adjectival uses like:

(16) There are several reasons. The most key one for many victims is ...

(2001 Women's Hour, BBC Radio 4 (15 Nov.))

(17) There are key fundamental flaws in this method.

(2002 Damian Byrne, abstract of article in online Journal of Language and Linguistics 1.1)

For Prn N, we have the analytical possibility of treating Prn as a subcategory of $\mathrm{N}$, since they are the two categories which can normally be head of NP. Historically there are shifts in the usage of OE mann to man, and arguably of self, body, and so on from the domain of $\mathrm{N}$ to that of Prn.

The relation between $\mathrm{D}$ and Prn is interesting. On one approach, the core of the $\mathrm{D}$ category is the articles, since almost their sole function is to determine a noun, and they cannot occur in any pronominal (that is, pro-NP) function. The remainder of the central determiners are then defined, at least in part, by contrastive distribution: any NP item which cannot co-occur with the articles is itself a determiner too. However, as is well known, apart from the articles, almost every determiner can occur in pronominal function.

(18) What do you think of this?

(19) Some are born great.

There are good reasons to analyse such items in two different ways: as an NP whose head (and sole constituent) is Prn, bringing out the analogy with

(20) What do you think of him? 
(21) They are born great.

Or as headless NPs with a missing or ellipted N, bringing out the analogy with

(22) What do you think of this idea?

(23) Some people are born great.

If we treat the possessive determiner my and the pronoun mine as variants of the same form, then there is even more overlap between D and Prn. (Historically, of course, that is exactly what they were.) Apparently rather similar is no and none.

The status of pronominal determiners is tricky, therefore, reflected in a rather confusing analysis in Quirk et al. (1985:870-873). Huddleston and Pullum — normally so decisive - actually treat pronominal determiners as a kind of blend, what they call the fused-head construction. I reproduce their diagram of an explicitly partitive fused-head (Huddleston and Pullum 2002:412):

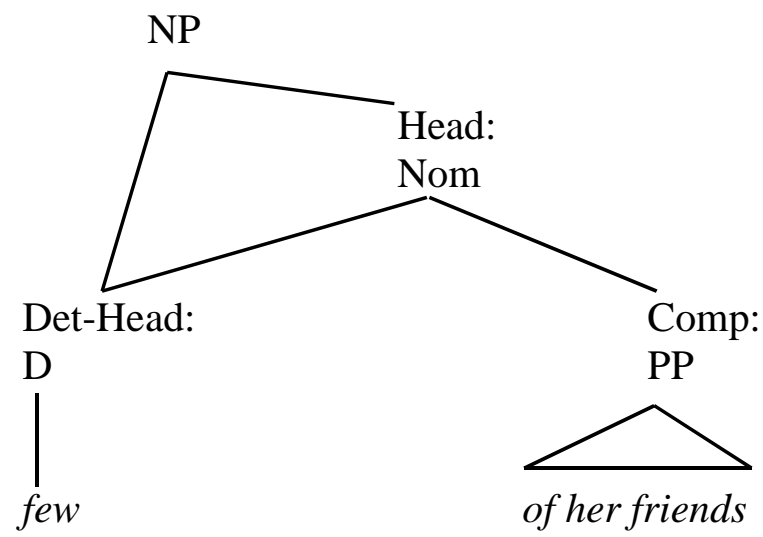

This is meant to capture the idea that certain kinds of pronominal determiner (though not personal pronouns, as in (25)-(26)), are simultaneously the grammatical part of the NP, acting as modifier to the lexical part, and the head. 
Coming at the gradient from the other side, note that even the core of Prn, the personal pronouns, have some determiner-like uses, though only the plural ones (and not 3 PL in standard):

(25) We/\#us scholars must stick together.

(26) You people are all wrong.

(27) You idiot(s)!

(28) \#Them ideas are really stupid.

Only the vocative (27) allows singular as well as plural. The Cambridge Grammar regards these, or at least (25)-(27), as determinatives in category, pointing out that the predeterminer all can precede the plural items as normal (Huddleston and Pullum 2002:374, 353 n.14). Dick Hudson has an analysis in which Det and Prn are unified as a single category on the same lines as analyses which treat adverbial particles as intransitive prepositions (Hudson 2000a); and of course there is the DP Hypothesis (Abney 1987).

As for the last pairing, D Adj, here we have a veritable minefield. Numerals have long been difficult to classify, but there are subtler difficulties too. Several of us have pointed out the difficulties of classifying such both as pre-determiner and postdeterminer (Denison 1998:117-18, Mackenzie 1997),

(29) such a nuisance

(30) no such luck

and the recent change from

(31) such another $\rightarrow$ another such 
Now there are at least two analyses (Huddleston and Pullum 2002:435, Spinillo 2003) which make a strong case for analysing such not as any kind of determiner in PDE but as A.

\section{Diachrony leaks}

Let us extend this discussion of the Det A boundary into diachrony. The Cambridge Grammar (Huddleston and Pullum 2002:392-3) regards various and certain as marginal determiners in PDE because of their occurrence in a partitive 'fused-head' construction (certain of the delegates), general semantics, non-generic semantics, and — for certain only — use with $a$ in

(32) This gave her a certain authority.

It is interesting to compare this predominantly syntactic account with $O E D$ 's comments on the lexical history:

I. 1. a. Determined, fixed, settled; not variable or fluctuating; unfailing. To avoid ambiguity from confusion with sense 7 , the adj. is sometimes put after its n., as a certain day, a day certain.

$[\ldots]$

II. 7. a. Used to define things which the mind definitely individualizes or particularizes from the general mass, but which may be left without further indentification [sic] in description; thus often used to indicate that the speaker 
does not choose further to identify or specify them: in sing. $=$ a particular, in $p l .=$ some particular, some definite.

Different as this seems to be from sense 1, it is hardly separable from it in a large number of examples: thus, in the first which follows, the hour was quite 'certain' or 'fixed', but it is not communicated to the reader; to him it remains, so far as his knowledge is concerned, quite indefinite; it may have been, as far as he knows, at any hour; though, as a fact, it was at a particular hour. (The absolute uses are in B 4-6.)

a1300 Cursor M. 8933 Ilk dai a certain hore| par lighted dun of heuen ture Angels. [etc.]

In other words, there are two very different lexical senses of certain which can be argued to be categorially different as well, yet there are many early examples which are equivocal. Given that the gradual — or at least graduated — nature of semantic change is reasonably widely accepted, why not allow that syntactic change may proceed by small steps too? I have alluded to many synchronic examples of gradience within the NP, where a word or a construction is neither one thing nor the other. Many will actually have started off as 'one thing' and moved during the history of English towards 'the other'. Note that this is not necessarily an argument for slowness of change, merely for graduatedness of at least some changes. 


\section{How intermediate forms arise}

How and why should this happen? One mechanism would be via what Quirk called serial relationship $(1965,1968)$. This is a plausible idea, though not part of a fully worked out model of language, in which new intermediate forms are made possible precisely because they share characteristics with, and therefore largely overlap with, already-existing grammatical forms on either side. One of his matrices (1968:Table 5, p.172) is reproduced here as Table 2 .

$$
\text { @@insert Table } 2 \text { about here }
$$

The columns 1-7 represent variant sequences in which the particular verbs shown at the left either are $(+)$, or are not $(-)$, attested, for example:

4. He would $X$ to come every day

5. He $X$ that

6. He $X$ us to come every day

Quirk writes (1968:172): “it is because of the gradience, in fact, that we [...] may find in speech 'mistaken' constructions of the form He doesn't want that anyone should ...". Later he explains

(33) He was said to be foolish in a similar way, as a passive that is fully acceptable despite the non-existence of any corresponding active (1968:176).

Another mechanism with some promise of forming part of a coherent linguistic theory would be dual inheritance, in a Construction Grammar framework where the 
properties of a given form may be inherited from more than one more general source construction (Goldberg 1995, Hudson 2000b), but contra (Bresnan 1997).

Either way, intermediate forms would arise when they serve some communicative purpose and because speakers — as opposed to linguists — are not confined to producing structures and grammars which are wholly self-consistent and maximally elegant and economical. If sufficiently useful, the innovations would diffuse into the language and might lead to permanent changes in the categories or structures of its grammar. But they might well not. Genuinely intermediate forms are often unstable historically.

\section{Why intermediate forms disappear}

If we assume that humans categorise the world - things in general, that is, and therefore also linguistic 'things' — roughly according to the principles identified by Rosch (1978, 1988), then one consequence is that we unconsciously adjust our categories and our categorisations to accommodate in the most satisfying way what we encounter. This was the assumption underlying Anthony Warner's (1990) account of the development of a modal category in English. Perhaps it is not too much of a stretch to assume that one solution to categorial awkwardness is for language users to find ways of avoiding the troublesome forms. (Again, this was applied by Warner to the loss of old preteritepresents like witan and certain lexical meanings of shall, can, etc. which fitted least comfortably into the emerging modal category.) The psycholinguistic experiment with pictures of cups and bowls is well known (Labov 1973). There the language user 
typically does make a choice, if sometimes an arbitrary one, as to where to draw the dividing line.

We have, then, the outline of a mechanism which disfavours intermediate forms. I have no explanation for why some intermediate forms seem nevertheless to show longterm stability; the best example I know is the $\mathrm{P} \sim \mathrm{A}$ form near, though most other former P A words have moved to one side or other of the boundary. ${ }^{5}$

With two opposing principles in tension we thus allow for both stability and change; it is worth noting, though, that such a diachronic model is rather at risk of posthoc-ery.

\section{Concluding remarks}

When a lexical item develops a new sense, there are often equivocal 'bridge' examples which users do not need to allocate to older or newer sense, since either works fine in the context. It might be compared to a superposition of quantum states whose wave function only collapses when observed. Linguists, however, tend to insist on observing, whereas ordinary speakers and hearers sometimes don't need to look analytically but only need to have the right chunk of language with the right overall interpretation. And I'm suggesting that this can happen not just in lexical semantics but in morphosyntax too. It might even happen with the example I used earlier to illustrate reanalysis:

(34) The car ran over a hedgehog. 
Perhaps neither speaker nor hearer will need to decide whether this is the prepositional or the phrasal verb. (And if that doesn't work, keep substituting different animals - frog, rabbit, sheep, elk — until you find the right size for this to be true.)

Much remains to be done at the diachronic level, including the tracing and verification of specific examples, and following enough of them to allow safer generalisations about the relative importance in language change of intermediate forms, and about their markedness and (in)stability. I don't think this is merely a notational variant of reanalysis.

What would such an enterprise buy us? It seems to me that the case for leakiness of grammar in synchrony is difficult to deny. The history of a language is the passage through successive synchronic states - or conversely, the simultaneous existence at any given moment of many historical states in a layered manner. (Notice that this latter reformulation sounds very much like a description of a grammaticalisation gradient, but I intend it to apply to a wider range of changes than grammaticalisations or lexicalisations.) Either way, a picture of change which both reflects and makes use of a more plausible picture of grammar, is in my opinion a desirable aim. 
Note

${ }^{1}$ I am grateful to Bill Croft and to the audience at 12ICEHL for comments, and to my daughter Rosie's timely contribution on (screen-)saving face.

${ }^{2}$ This section is adapted from draft material prepared for Hogg and Denison (in prep.).

${ }^{3}$ Later he discusses the arbitrariness of parts of speech and concludes "how they not merely grade into each other but are to an astonishing degree actually convertible into each other" (Sapir 1921:118). Once again, though, this is really to do with crosslinguistic comparison rather than assignment of an individual word in one language to a word class.

${ }^{4}$ I have shortened pronoun as Prn to distinguish explicit pronouns from the empty category Pro of GB Theory.

${ }^{5}$ See now Aarts, Denison, Keizer and Popova (in press, 2004:Introduction) for a review of work on mixed and gradient categories. 


\section{References}

Aarts, Bas, David Denison, Evelien Keizer and Gergana Popova (eds.) (in press, 2004) Fuzzy Grammar: A reader. Oxford: Oxford University Press.

Abney, S P. 1987. The English Noun Phrase in its Sentential Aspect. PhD dissertation, MIT.

Bresnan, Joan. 1997. "Mixed Categories as Head Sharing Constructions". http://wwwlfg.stanford.edu/lfg/ms/ms.html

Croft, William. 2000. Explaining Language Change: An evolutionary approach. (= Longman Linguistics Library.) Harlow: Longman.

Denison, David. 1998. "Syntax". The Cambridge History of the English Language, ed. by Suzanne Romaine, vol. 4, 1776-1997, 92-329. Cambridge: Cambridge University Press.

Denison, David. 2001. “Gradience and Linguistic Change”. Historical Linguistics 1999: Selected papers from the 14th International Conference on Historical Linguistics, Vancouver, 9-13 August 1999, ed. by Laurel J. Brinton, 119-144. (= Current Issues in Linguistic Theory, 215.) Amsterdam and Philadelphia PA: John Benjamins.

Goldberg, Adele E. 1995. Constructions: A Construction Grammar approach to argument structure. Chicago and London: University of Chicago Press.

Hogg, Richard M. and David Denison, eds. in prep. A History of the English Language. Cambridge: Cambridge University Press.

Huddleston, Rodney and Geoffrey K. Pullum. 2002. The Cambridge Grammar of the English Language. Cambridge: Cambridge University Press.

Hudson, Richard. 2000a. "Grammar without Functional Categories". Syntax and Semantics, ed. by Robert D. Borsley, vol. 32, 7-35. New York: Academic Press.

Hudson, Richard.2000b. “*I amn't”. Language 76.297-323.

Labov, William. 1973. "The Boundaries of Words and their Meanings". New Ways of Analyzing Variation in English, ed. by Charles-James N. Bailey and Roger W. Shuy, 340-373. Washington DC: Georgetown University Press.

Lightfoot, David W. 1979. Principles of Diachronic Syntax. (= Cambridge Studies in Linguistics, 23.) Cambridge etc: Cambridge University Press.

Mackenzie, J. Lachlan. 1997. "Grammar, Discourse and Knowledge: The use of such". Studies in English Language and Teaching: In honor of Flor Aarts, ed. by J. Aarts, Inge de Mönnink and H. Chr Wekker, 85-105. Amsterdam and Atlanta GA: Rodopi.

Pintzuk, Susan. 1991. Phrase Structures in Competition: Variation and change in Old English word order. PhD dissertation, University of Pennsylvania.

Quirk, Randolph.1965. "Descriptive Statement and Serial Relationship". Language 41.205-217.

Quirk, Randolph. 1968. "Descriptive Statement and Serial Relationship”. Essays on the English Language, Medieval and Modern, ed. by Randolph Quirk, 167-183. London: Longman. 
Quirk, Randolph, Sidney Greenbaum, Geoffrey Leech and Jan Svartvik. 1985. A Comprehensive Grammar of the English Language. London and New York: Longman.

Raumolin-Brunberg, Helena. 2002. "Stable Variation and Historical Linguistics". Variation Past and Present: VARIENG studies on English for Terttu Nevalainen, ed. by Helena Raumolin-Brunberg, Minna Nevala, Arja Nurmi and Matti Rissanen, vol. 61, 101-116. (= Mémoires de la Société Néophilologique de Helsinki.) Helsinki: Société Néophilologique.

Rosch, Eleanor. 1978. "Principles of Categorization". Cognition and Categorization, ed. by Eleanor Rosch and B. B. Lloyd, 27-48. Hillsdale NJ: Lawrence Erlbaum Associates.

Rosch, Eleanor. 1988. "Coherences and Categorization: A historical view". The Development of Language and Language Researchers: Essays in honor of Roger Brown, ed. by F. Kessel, 373-392. Hillsdale NJ: Lawrence Erlbaum.

Sapir, Edward. 1921. Language: An introduction to the study of speech. New York: Harcourt Brace.

Spinillo, Mariangela.2003. "On Such". English Language and Linguistics 7.

Warner, A. R. 1990. "Reworking the History of English Auxiliaries". Papers from the 5th International Conference on English Historical Linguistics: Cambridge, 6-9 April 1987, ed. by Sylvia Adamson, Vivien A. Law, Nigel Vincent and Susan Wright, 537-558. (= Current Issues in Linguistic Theory, 65.) Amsterdam and Philadelphia: John Benjamins.

Warner, Anthony. 2002. "Affirmative and other DOs before 1600". Paper presented at York-Holland Symposium on the History of English Syntax, 1st meeting, York, 21-22 Apr 2002.

van der Wurff, Wim.1992. "Syntactic Variability, Borrowing, and Innovation". Diachronica 9.61-85. 


\section{Tables}

\begin{tabular}{|lcccc|}
\hline & D & A & N & Prn \\
\hline lexical & - & + & + & - \\
\hline iterate & - & + & $(-)$ & - \\
\hline number marking & $(-)$ & - & + & + \\
\hline comparison & - & + & - & + \\
\hline case marking & - & - & - & $?$ \\
\hline can act as predicate & - & + & - & \\
\hline
\end{tabular}

Table 1: Distinctive features of some NP categories

\begin{tabular}{|c|c|c|c|c|c|c|c|}
\hline & 1 & 2 & 3 & 4 & 5 & 6 & 7 \\
\hline intends & + & + & + & + & + & + & + \\
\hline wants & + & + & + & + & + & + & - \\
\hline seems & + & + & + & + & ? & - & - \\
\hline has & + & + & + & & - & - & - \\
\hline used & + & + & & - & - & - & - \\
\hline is & + & & - & - & - & - & - \\
\hline may & & - & - & - & - & - & - \\
\hline
\end{tabular}

Table 2: An example of serial relationship 